Neurosurg Focus 18 (5):E3, 2005

\title{
Trigeminal neuralgia: definition and classification
}

\author{
Jorge L. Eller, M.D., Ahmed M. Raslan, M.D., ANd Kim J. Burchiel, M.D. \\ Department of Neurological Surgery, Oregon Health \& Science University, Portland, Oregon
}

\begin{abstract}
Based on specific, objective, and reproducible criteria, a classification scheme for trigeminal neuralgia (TN) and related facial pain syndromes is proposed. Such a classification scheme is based on information provided in the patient's history and incorporates seven diagnostic criteria, as follows. 1) and 2) Trigeminal neuralgia Types 1 and 2 (TN1 and TN2) refer to idiopathic, spontaneous facial pain that is either predominantly episodic (as in TN1) or constant (as in TN2) in nature. 3) Trigeminal neuropathic pain results from unintentional injury to the trigeminal nerve from trauma or surgery. 4) Trigeminal deafferentation pain results from intentional injury to the nerve by peripheral nerve ablation, gangliolysis, or rhizotomy in an attempt to treat either TN or other related facial pain. 5) Symptomatic TN results from multiple sclerosis. 6) Postherpetic TN follows a cutaneous herpes zoster outbreak in the trigeminal distribution. 7) The category of atypical facial pain is reserved for facial pain secondary to a somatoform pain disorder and requires psychological testing for diagnostic confirmation. The purpose of a classification scheme like this is to advocate a more rigorous, standardized natural history and outcome studies for $\mathrm{TN}$ and related facial pain syndromes.
\end{abstract}

KEY WORDS - trigeminal neuralgia • facial pain • trigeminal nerve

\section{OVERVIEW AND RATIONALE}

Trigeminal neuralgia has been referred to in the medical literature for centuries. References to unilateral facial pain causing facial spasms can be seen in the writings of Aretaeus of Cappodocia in the 2nd century A.D. ${ }^{20}$ and those of the Arab physician Jujani in the 11th century A.D. ${ }^{1}$ John Fothergill, ${ }^{10}$ in a paper published in 1773, described the typical features of TN, including its paroxysmal nature and association with triggering factors such as eating, speaking, or touching the face. In 1756, the French surgeon Nicholas André ${ }^{2}$ coined the term "tic douloureux" to describe at least three patients with TN treated by neurectomy. ${ }^{4}$

Over the last three centuries, the clinical features of socalled "classic" TN have been well documented and are now universally recognized. A diagnosis of TN is always based on the patient's clinical history. The hallmark pain is described as agonizing, paroxysmal, and lancinating. Pain is perceived in one or more divisions of the trigeminal nerve, is usually brief, with repetitive bursts every few seconds, and may be triggered by activities such as chewing, speaking, swallowing, touching the face, or brushing the teeth. As a result, hygienic activities and even eating are often avoided. Pain is virtually always unilateral, with rare reports of bilateral symptoms. Pain-free intervals are common and may continue for weeks or as long as a few years. Recurrences are common and are usually experienced in the same region as the initial pain. Results of neurological examination are almost always normal, although with careful testing ${ }^{9}$ a slight degree of sensory loss can be detected.

Abbreviations used in this paper: $\mathrm{MS}=$ multiple sclerosis; $\mathrm{TN}=$ trigeminal neuralgia; TN1 $=$ TN Type $1 ;$ TN2 $=$ TN Type 2 .
The pathophysiological features of classic TN relate to compression of the trigeminal nerve root by a blood vessel at or near the root entry zone. ${ }^{11,13,14,16}$ Ectopic action potential generation in the sensory root of the nerve may be responsible for the typical, episodic, electric, lancinating pain. ${ }^{8}$ Important contributing factors may be central and peripheral demyelination, which occur as a result of nerve root injury. ${ }^{12,15}$ Improvement in trigeminal nerve conduction after decompression, as shown by intraoperative electrode recordings, in association with postoperative pain relief in the vast majority of patients, corroborates evidence that compression of the trigeminal nerve by a blood vessel is a major causative or contributive factor. ${ }^{3,18,19}$

Pain in the distribution of the trigeminal nerve that is described as constant, aching, throbbing, or burning has traditionally not been considered "true" TN, and as a result, nonspecific terms such as atypical TN or atypical facial pain have surfaced. The precise meaning of "atypical" facial pain remains elusive, and it is used as a catchall phrase to identify any facial pain that does not fit the classic clinical diagnostic picture of TN. The term "atypical" combines several different facial pain syndromes, and it therefore hinders and prevents further understanding of the pathophysiological origins of the disease and the development of specific treatment modalities.

We propose a new classification scheme for TN and related facial pain syndromes, one based on information obtained from the patient's medical history and with which we attempt to guide the differential diagnosis by using objective and reproducible criteria. This classification will provide a standardized framework with which the natural history and pathophysiological features of different facial pain syndromes can be better understood. 


\section{CLASSIFICATION SYSTEM}

\section{Idiopathic TN1 and TN2}

In the classification scheme we propose, a diagnosis that was previously referred to as classic or typical TN is referred to as TN1. As described earlier, this is an idiopathic sharp, shooting, electrical shock-like, episodic pain lasting several seconds, with pain-free intervals between attacks. This diagnosis is fairly straightforward and most neurosurgeons are familiar with this clinical entity.

We propose that $\mathrm{TN} 2$ describes idiopathic trigeminal facial pain that is aching, throbbing, or burning for more than $50 \%$ of the time and is constant in nature (constant background pain being the most significant attribute). There may be a minor component of sharp, episodic pain. In the absence of a demonstrable structural pathological entity, we theorize that if left untreated, TN1 progresses toward TN2 and signifies further neural injury. ${ }^{6,7,9}$ In cases of facial pain with the features of TN2, the likelihood of detecting a structural entit, such as a tumor or a vascular malformation in the posterior fossa is higher. ${ }^{5}$ With this in mind, the neurosurgeon should obtain imaging studies in these patients before a definitive diagnosis of TN2 is made.

\section{Neuropathic and Deafferentation TN}

Pain in the distribution of the trigeminal nerve in patients with a history of injury to the trigeminal system identifies a specific subset of cases. The patients in these cases are suffering from a form of neuropathic pain involving the trigeminal system, as opposed to the idiopathic forms of TN (TN1 and TN2). This group of patients is divided into two subsets. The first, trigeminal neuropathic pain, includes patients who have suffered unintentional injury to the trigeminal system as a result of facial trauma; oral surgery; ear, nose, and throat surgery; skull base surgery; posterior fossa surgery; or stroke. The second, trigeminal deafferentation pain, includes patients who received intentional injury to their trigeminal system, such as neurectomy, gangliolysis, rhizotomy, nucleotomy, tractotomy, or other denervating procedures. Trigeminal neuropathic pain mostly constitutes

TABLE 1

Definition and classification of TN

\begin{tabular}{ll}
\hline \hline \multicolumn{1}{c}{ Defining Symptomatology } & \multicolumn{1}{c}{ Diagnostic Classification } \\
\hline $\begin{array}{l}\text { idiopathic } \\
\text { sharp, shooting, electrical shock-like, } \\
\quad \text { episodic pain }\end{array}$ & $\mathrm{TN} 1$ \\
$\begin{array}{l}\text { aching, throbbing, burning, }>50 \% \\
\quad \text { constant pain }\end{array}$ & $\mathrm{TN} 2$ \\
$\begin{array}{l}\text { trigeminal injury } \\
\text { unintentional (facial trauma; oral op; }\end{array}$ & trigeminal neuropathic pain \\
$\quad \begin{array}{l}\text { ear, nose, \& throat op; skull base } \\
\text { op; posterior fossa op; or stroke) }\end{array}$ & \\
$\begin{array}{l}\text { intentional (neurectomy, gangliolysis, } \\
\text { rhizotomy, nucleotomy, tractotomy, }\end{array}$ & trigeminal deafferentation pain \\
$\quad \begin{array}{l}\text { or other denervating procedure) } \\
\text { associated w/ MS } \\
\text { resulting from an outbreak of facial } \\
\text { herpes zoster }\end{array}$ & $\begin{array}{l}\text { symptomatic TN } \\
\text { somatoform pain disorder }\end{array}$ \\
\hline
\end{tabular}

* Evaluation needed with psychological testing prior to confirmation.

\section{J. L. Eller, A. M. Raslan, and K. J. Burchiel}

an unremitting throbbing or burning in the affected area, whereas trigeminal deafferentation pain is described as burning, crawling, itching, or tearing. Anesthesia dolorosa, an extreme condition, is described as excruciating pain perceived in an insensate region of the face.

\section{Symptomatic and Postherpetic TN}

Two separate criteria easily identified in the patient's history are worthy of inclusion. One, symptomatic TN, describes the association of TN with MS. In patients with TN who are younger than 40 years of age, particularly those with evidence of sensorimotor dysfunction, a diagnosis of MS should be considered. Approximately $1 \%$ of patients with TN have MS; conversely, the incidence of TN in the population of patients with MS is between 1 and $3 \% .{ }^{17}$ The pathological origin in these cases appears to be demyelination, either in the trigeminal nerve or within the descending tract of the trigeminal system in the brainstem. Pain is characteristically either episodic or constant in nature. The other, postherpetic TN, describes trigeminal pain resulting from an outbreak of facial herpes zoster. This condition usually affects the first division and is marked by the development of allodynia superimposed on a burning dysesthesia. Trophic changes may be noted.

\section{Atypical Facial Pain}

A final criterion in our classification scheme is atypical facial pain. We propose that this term be limited to patients reporting facial pain in the context of a somatoform pain disorder. These patients usually experience bilateral facial pain, which spreads outside a trigeminal distribution, along with multiple pain complaints in other body regions, including diagnostic clustering such as fibromyalgia or chronic fatigue syndrome. Patients must be evaluated using psychological testing prior to confirmation of this diagnosis.

\section{CONCLUSIONS}

The major advantage of the classification scheme proposed, which is summarized in Table 1, is to provide a simple framework with which even the most inexperienced neurosurgeon can make an accurate diagnosis and provide adequate advice regarding treatment modalities and prognosis. A further advantage is more accurate, rigorous, and precise communication among different specialists treating patients with TN and related facial pain syndromes, with facilitation of additional natural history and outcome studies in the field of facial pain management.

\section{References}

1. Ameli NO: Avicenna and trigeminal neuralgia. J Neurol Sci 2: 105-107, 1965

2. André N: Observations Pratiques sur les Maladies de l'Urethre, et sur Plusieurs Faits Convulsifs, \& la Guérison de Plusieurs Maladies Chirurgicales Avec la Décomposition d'un Remède Propre à Réprimer la Dissolution Gangréneuse \& Cancéreuse, \& à la Réparer; Avec des Principes qui Pourront Servir à Employer les Différens Caustiques. Paris: Delaguette, 1756

3. Barker FG II, Jannetta PJ, Bissonette DJ, et al: The long-term outcome of microvascular decompression for trigeminal neuralgia. N Engl J Med 334:1077-1083, 1996 
4. Brown JA, Coursaget C, Preul MC, et al: Mercury water and cauterizing stones: Nicolas André and tic douloureux. J Neurosurg 90:977-981, 1999

5. Bullitt E, Tew JM, Boyd J: Intracranial tumors in patients with facial pain. J Neurosurg 64:865-871, 1986

6. Burchiel KJ: A new classification for facial pain. Neurosurgery 53:1164-1167, 2003

7. Burchiel KJ, Slavin KV: On the natural history of trigeminal neuralgia. Neurosurgery 46:152-154, 2000

8. Devor M, Govrin-Lippmann R, Rappaport ZH: Mechanism of trigeminal neuralgia: an ultrastructural analysis of trigeminal root specimens obtained during microvascular decompression surgery. J Neurosurg 96:532-543, 2002

9. Elias WJ, Burchiel KJ: Trigeminal neuralgia and other craniofacial pain syndromes: an overview. Semin Neurosurg 15:59-69, 2004

10. Fothergill J: Of a painful affection of the face. Medical observations and inquires by a society of physicians. Med Observ Inquir 5:129-142 1773

11. Fromm GH, Sessle BJ: Trigeminal Neuralgia: Current Concepts Regarding Pathogenesis and Treatment. Boston: Butterworth-Heinemann, 1991

12. Golby AJ, Norbash A, Silverberg GD: Trigeminal neuralgia resulting from infarction of the root entry zone of the trigeminal nerve: case report. Neurosurgery 43:620-622, 1998

13. Haines SJ, Jannetta PJ, Zorub DS: Microvascular relations of the trigeminal nerve. An anatomical study with clinical correlation. J Neurosurg 52:381-386, 1980
14. Hamlyn PJ, King TT: Neurovascular compression in trigeminal neuralgia: a clinical and anatomical study. J Neurosurg 76: 948-954, 1992

15. Hilton DA, Love S, Gradidge T, et al: Pathological findings associated with trigeminal neuralgia caused by vascular compression. Neurosurgery 35:299-303, 1994

16. Jannetta PJ: Arterial compression of the trigeminal nerve at the pons in patients with trigeminal neuralgia. J Neurosurg 26 (Suppl):159-162, 1967

17. Jensen TS, Rasmussen P, Reske-Nielsen E: Association of trigeminal neuralgia with multiple sclerosis: clinical and pathological features. Acta Neurol Scand 65:182-189, 1982

18. Leandri M, Eldridge P, Miles J: Recovery of nerve conduction following microvascular decompression for trigeminal neuralgia. Neurology 51:1641-1646, 1998

19. Nurmikko TJ, Eldridge PR: Trigeminal neuralgia—pathophysiology, diagnosis and current treatment. Br J Anaesth 87: 117-132, 2001

20. Rose FC: Trigeminal neuralgia. Arch Neurol 56:1163-1164, 1999

Manuscript received March 17, 2005.

Accepted in final form April 8, 2005.

Address reprint requests to: Kim J. Burchiel, M.D., Department of Neurological Surgery, L-472, Oregon Health \& Science University, 3181 SW Sam Jackson Park Road, Portland, Oregon 972393098. email: burchiek@ohsu.edu. 